\title{
Regulating Lines: Making Use of Imaginary Lines and Design Principles in the Studio
}

\author{
Bruce Dvorak \\ Department of Landscape Architecture and Urban Planning, Texas A\&M University, College Station, USA
}

\section{Email address:}

bdvorak@tamu.edu

\section{To cite this article:}

Bruce Dvorak. Regulating Lines: Making Use of Imaginary Lines and Design Principles in the Studio. Science Journal of Education. Vol. 5, No. 5, 2017, pp. 225-231. doi: 10.11648/j.sjedu.20170505.18

Received: September 28, 2017; Accepted: October 23, 2017; Published: November 16, 2017

\begin{abstract}
Regulating lines are visible or implied lines used to compose and construct artifacts, buildings, landscapes or other objects. In landscape architecture, regulating lines have been used from antiquity. During the renaissance, for example, many French formal gardens were organized with symmetry and Euclidean geometry as organizing elements. These formal gardens often had visible or implied regulating lines. Contemporary use and asymmetrical use of regulating lines can be observed in the works of Dan Kiely, Peter Walker, Andrea Cochran, Marth Swartz and others. In landscape architecture, the use of regulating lines and the articulation of a method to design with regulating lines is not well-developed. There are several introductory textbooks in landscape architecture education which mention regulating lines, but these references lack detail regarding how regulating lines can be observed or used. This paper explores a case study example of how regulating lines were used as a teaching tool. As an exercise in the design studio, landscape architecture students were given assignments to make a landscape design with the use of regulating lines. One case study is presented to demonstrate how regulating lines can be used by students and faculty in the design studio. Regarding application to professional practice, the design of some informal designs may not be aided by regulating lines such as meandering designs or highly irregular properties. This paper aims to encourage dialog and critique of using regulating lines as a teaching tool, and to demonstrate their potential appropriateness or usefulness.
\end{abstract}

Keywords: Proportion, Unity, Process, Revision, Design

\section{Introduction}

The design process often requires multiple iterations before a designer arrives at a final form that is pleasing to the eye, and meets the intended goals and objectives [1,2]. There is no one formula that a begining designer can use to easily resolve form and aesthetic expectations; however, there is a common way of learning design. Students learn design "by doing", and by reflecting upon the critiques of the design by an experienced designer [2, 3]. In landscape architecture education, the conventional pedagogy used to teach design takes place in a juried studio environment. Students present their "in progress" designs to experienced educators to recieve feedback about multiple aspects of the design [3] including design principles [4]. Although there are resoucres available to aid the landscape architecture student and instructor [3-7], there are few that describe in detail how an instructor can engage students to see how design elements (points, lines, plane, form, color, texture), can be arranged to accomplish ordering principles such as unity, harmony, emphasis, balance, scale, and proportion. The design process in landscape architecture is well-documented in terms of its traditional sequence including: site inventory, analysis, program and development of design goals, conceptual design through design development, and final design as a site plan or master plan $[3,5,6]$. Although this process may be familiar to a landscape architecture studio instructor, publications regarding the iterative activity of a student working out design form elements and principles is not welldocumented. Most writing is terse regarding the process of how students can evolve a landscape design in its form relations.

In the field of architecture, a similar process is used [8]. With the design of buildings, however, program, design style, and structural and technical feasibility can be unified in a design process. Regulating lines can align a building's 
features into a proportional solution that also corresponds with its structural elements, doors and windows [9].

Regulating lines are visible or implied lines used to compose and order and construct artifacts, artwork, buildings, landscapes, web pages or other designed objects $[10,11]$. The Mona Lisa by Leonardo da Vinci, for example, has various interpretations of regulating lines and compositional line patterns such as the golden spiral and the golden rectangle. In his Robe house, Frank Lloyd Wright used diagonal regulating lines abstracted from the form of a grid-like arrangement of seeds on a head of wheat. The wheat "grid" was used in the pattern, as well as the diagonal arrangement of windows, doors and the entire structure [9]. Regulating lines were commonly used in architecture to resolve design elements with principles prior to the Victorian era, and today some argue for a return to their exploration and use $[9,12]$. The use of regulating lines was not a way to force or make design a formula, but a tool to resolve ideas already in motion [9].

Nathan Hale, in The Old Way of Seeing suggests, "In my own experience, and from what I can tell of others', the pattern of regulating lines is usually unknown or only partially known, to the designer. To set out deliberately to design to a predetermined pattern risks losing the connection with intuition; it can lead to dead designs, because the source of the most exciting inspirations is unconscious" [9]. This suggests that the patterns or structure used as a regulating device can help refine ideas, but not become the idea itself. Hale clarifies further that "Sometimes the designer arrives at patterns through slow deliberation, but often they are created very rapidly." So the use of regulating lines can evolve along with a design or sometimes arrive as the concept is developed spontaneously.

In landscape architecture, regulating lines have been used from antiquity. During the renaissance for example, French formal gardens strongly expressed axial alignments with strong geometrical designs and often with bi-lateral symmetry with secondary regulating lines [13]. The placement, form, and alignment of rocks in the Ryōan-ji temple garden in Kyoto, Japan (circa 1488) makes use of regulating lines in an asymmetrical and less formal arrangement [10, 14]. Contemporary use of organizing lines and grids in landscape architecture can be observed in the works of Dan Kiely, Peter Walker, Marth Swartz and many others [15].

In landscape architecture education, the use of regulating lines and the articulation of a method to design with regulating lines is not well developed. There are a few introductory landscape architecture design textbooks that mention regulating lines directly $[3,5,7,16]$, but there is little development of how they can be used by students in the landscape architecture studio to generate design forms and evolve proportion and a harmonious composition. This paper explores the use of regulating lines in the design studio as a tool to assist students throughout the design process. Unity, proportion and rhythm have frequently been quoted as aided by regulating lines [9].

\section{Methods}

During the design process, it is common for designers to sometimes struggle to arrange design elements and resolve landscape forms according to design principles including proportion, unity, balance and repetition. To investigate the use of regulating lines during the design process, fifteen graduate students were introduced to regulating lines as part of a hypothetical design project. This design studio was a fifteen week course which allowed students to develop a master plan for a transit-oriented development project in design teams. During the last third of the semester, students individually designed one element of the master plan [17].

As a case study to introduce regulating lines in the studio, students were asked to make use of regulating lines during the process of a landscape design project during the regular semester coursework. At the beginning of the individual work assignment, students were given a lecture (March 31, 2014) with images to introduce the concept of regulating lines (examples from Motloch, Hale, Doczi and others) to students as a way for them to explore their use and to resolve design compositions. Examples were shown of how previous landscape architecture students at Texas A\&M University used regulating lines in form resolution exercises through a series of iterations. The landscape design assignment was given, without any formal method for the instructor to graphically record feedback given to the students. The instructor gave verbal critique during design studio based upon the student's progress. Students that made good example of the use of regulating lines during the exercises were asked to keep their work and photograph their progress prior to each critique. After the end of the semester, the instructor reviewed the work and made preliminary graphical notes about how students used regulating lines.

A series of design evolutions by one student is presented here as a case study example of how regulating lines were used to improve proportion, harmony and other design principles. The figures show one student's design development of a two-block city park over a three week period (the student requested anonymity). The park program included space for small to large gatherings, an outdoor music performance area, accommodations for the public to arrive via multi-modal paths such as pedestrian, auto, public transit, and space for the setup of temporary display or merchandice booths (shade structures) during annual festival events such as arts and crafts fairs.

The student did not state any identifiable regulating line pattern during the beginning stages of the design process. Later in the design process (stages 3-5) the student made conscious efforts to make use of regulating lines. Students signed up for twenty-minute design critiques. Discussion during design crits early in the process were targeted towards aligning program with form resolution and site context. No physical record of the design crits by the instructor was photographed or retained. The work of the student is shown in graphic form in the progression of figures 1-5. Where red lines are shown, these depict the instructor's interpretation of 
the student's use of regulating lines. The instructor (author) provided verbal feedback to the student, and on several occasions' graphical feedback was provided on trace paper. The discussion regarding regulating lines is shown (postproject) in this paper for the purposes of demonstrating how the student apparently formed a design using regulating lines. The student design features and response to the critique are discussed first, and the analysis of regulating lines follows.

\section{Results}

Figure 1 shows the student's first iteration of a conceptual design for the two block park. It features a large grassed open space, and a water feature with a flow channel. The image on the left is the student's design, and the image on the right shows the addition of the instructor's assumption of regulating lines as red lines.

The park includes a water feature as a focal point in the upper left corner of the park. The student had investigated the work of landscape architect Herbert Dreiseitl, and was inspired to mimic the forms of water and use of water similar to some of the form compositions of Herbert's plaza and park spaces [18]. The water feature was not part of the initial program for the park, but the student wanted to include one. The water channel flows into a linear pond feature with a stage area shown as an irregular grey pavement. The idea

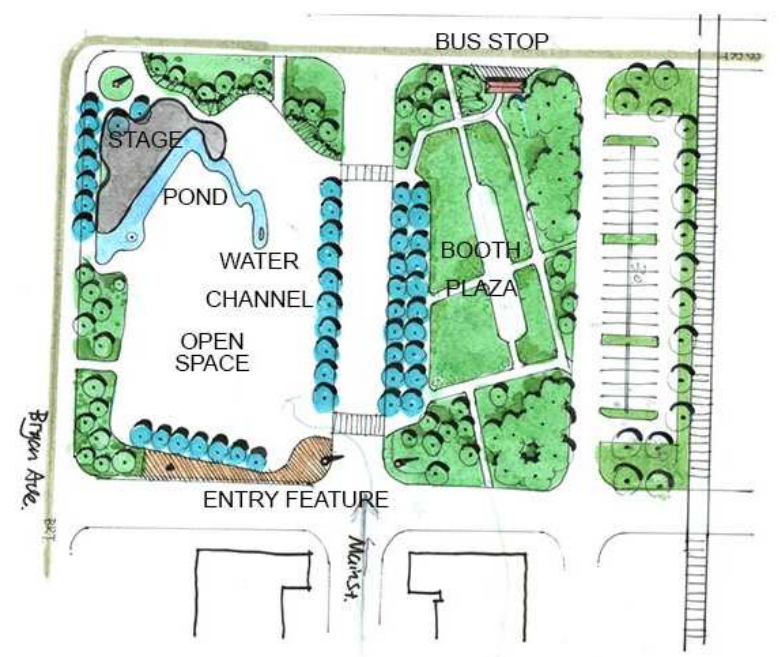

was to separate the stage with the water channel. A large open space is provided for people attending a music or stage event. A bus stop with a shelter structure and seating space is provided.

Regarding form development, the student began (this design iteration) with an asymmetrical composition dominated by rectangular defined spaces and some paths aligned at counter angles. A few paths allow for entrance into the spaces; however there is little harmony between the elements of the two city blocks. The red lines on the right side diagram show the dominant regulating lines for the composition. The water feature forms a 45-degree angle to the road intersection and the flow channel accentuates the 45degree line. The water feature appears to not align with other elements at important locations or angles. The small block has a double row of trees and an angled open space for arts and crafts display booths. This paved area is a dominant feature, but it appears to not align well with other elements. The alignment of many program elements and design features (paths, open space, canopy trees) is not yet resolved according to the principles of balance, proportion and focal points. The design critique focused on increasing unity between the two blocks, reducing or eliminating the water feature (safety concerns), and the improvement of spatial definition with more canopy trees.

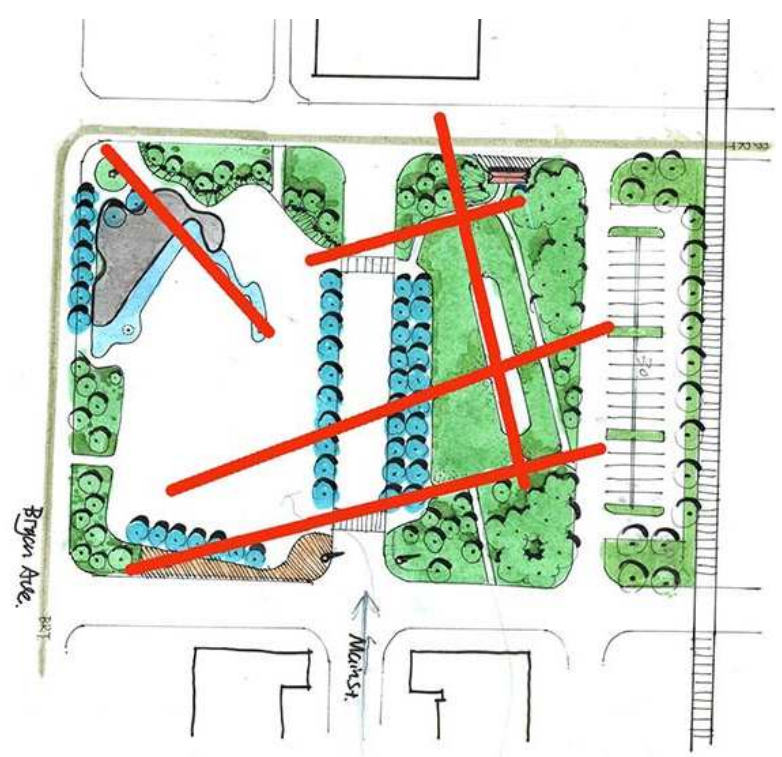

Figure 1. Image of park at first design iteration (left) and regulating line assessment (right). Regulating lines (in red) reveal that the design principles such as balance, unity, etc. are lacking.

The next design iteration by the student is shown in Figure 2. The unity between the two blocks is greatly improved. The red lines show how the site features and sight lines begin to align with the stage as a focal point and the forms of the two sides begin to become ordered. The large block now includes a performance stage with small amphitheater. Trees are aligned to define the edge of the amphitheater and extend lines from the stage into the open space. The open space however, is divided by water channels and trees. These features reduce the potential for open space activities. The water feature separates the stage area from the gathering space, and defines an open space. It parallels a pathway that connects to an entrance pavilion. The small block has curving paths that intersect angled promenades.

The critique (of the revised design) identified that although unity is improved between the two blocks, the function of the individual spaces needs improvement. There was also a need to revisit the water feature (reduce its complexity). The open space needed to provide for larger gatherings. The small block needed refinement of programed elements. 


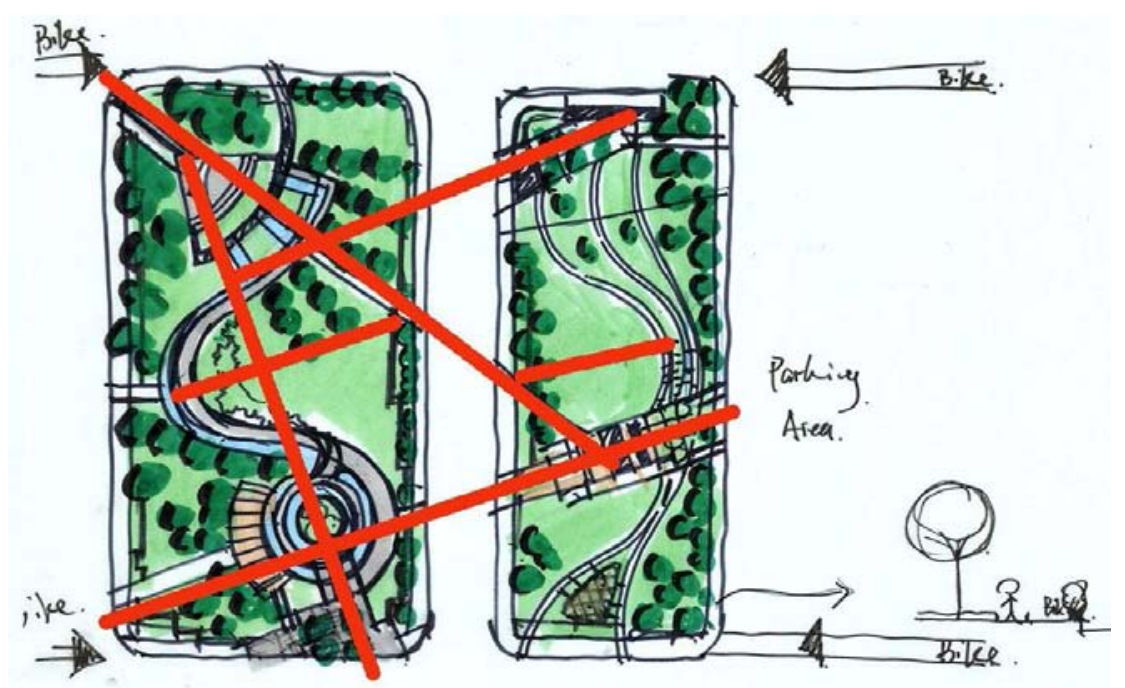

Figure 2. Schematic shows regulating lines overlaid on the second design iteration. The alignment of park pathways and features have increased in unity and visual harmony.

The next iteration of the design (Figure 3) included a reduction in the stage size, removal of the water feature, and the introduction of an entry plaza with seating. The small block included two paths in the lower half that accommodate tables with shade structures, a small open space and a seating area that faced outward. Regulating lines are shown to identify the axial lines that now link the stage area with the entry plaza in the large block and the cross-axial lines that align to focal points in the smaller block. Bus rapid transit lanes are shown in blue on the adjacent streets. The short road that divides the two blocks includes a mid-block crossing with a tree lined median.

The design critique included that the design program could better develop the large open space since trees now occupied the majority of the large block area. The seating area in the small block (semi-circular area near the top) is facing away from the park and towards an abandoned lot. Refocusing the seating area to engage the park could lead to a better social interaction and face the open space of the small block. There were a number of trees in the park throughout, but they were not effectively defining and making usable space. Trees were being used to fill space, but not make space.

Regulating lines in the central area acknowledge the formation of rectangular and orthogonal relationships between landscape features of the two blocks. During the critique it was emphasized that there could be a strengthening of these relationships. Although the curved path system on the left (large) block was repeated in form on the right (small) block, there was little programmatic benefit by repeating these forms in terms of defining a positive and usable open space. The path systems were the dominant feature, and divided the open spaces into smaller and less important spaces. The paths could be used to define and engage usable space.

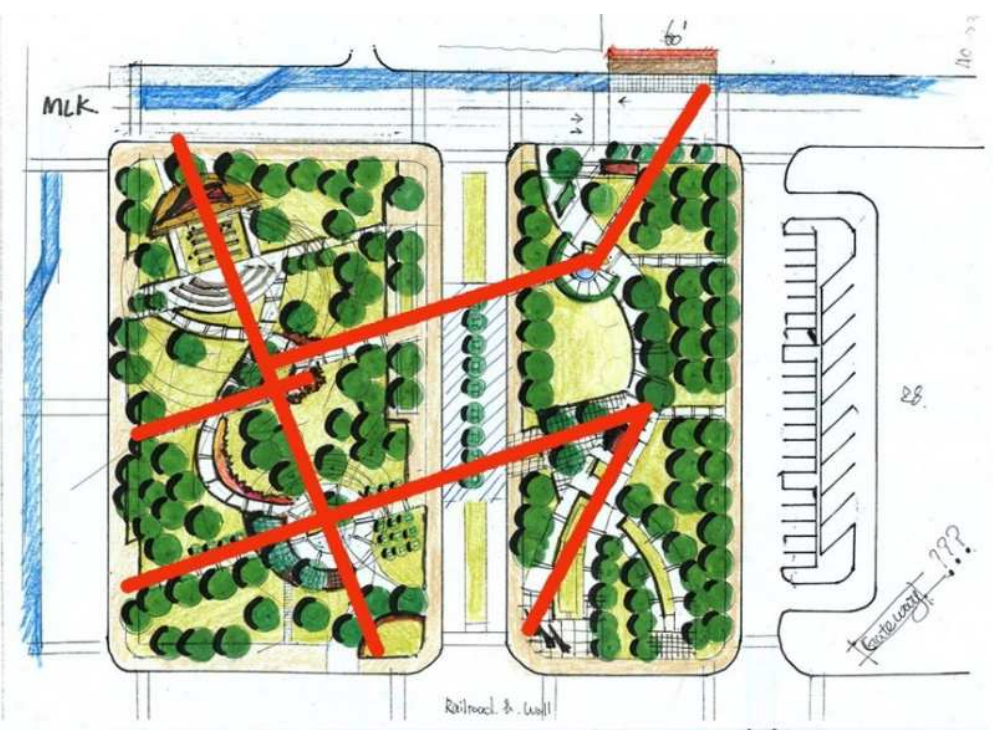

Figure 3. Schematic of the third design iteration demonstrates that the features in the two separate blocks are more unified in their alignment (emphasis, balance and proportion), but are lacking in potential to be useful and programmable space. 
At this point in the design process, the student began to express some frustration. The deadline was approaching within a week, and the student believed that the design was nearly complete. Although the design critique ended with a clear understanding of the content of the critique (improve the potential function and usability of the spaces between the paths), it was not clear if the student would make efforts to improve the design. Figure 4 shows the revised design with a major reconstruction of the path system to better embrace and form the open space. With this iteration, it is apparent that the open space was deliberately defined by the path system. The path systems on both the large and small blocks are now aligned at the same angle. The central space in the mid-block location is emphasized, and the water inspired curved path was removed. The other dramatic shift in the design process was that the student spent less effort working through color schemes and more attention to path systems and their relationships to programmable open space. A proportioned rectangular form now appears to link both blocks as a secondary regulating line system. Semi-circular spaces are introduced. These function as a terminus and focal points. These focal points are aligned with the adjacent pathways and secondary site elements which increase the design's functionality.

The design critique to the student at this point, with less than a week remaining, was to continue to resolve the interior spaces, and to potentially use canopy trees to clearly define programmable space. The outer edges of the park could be better linked to their interior connections.

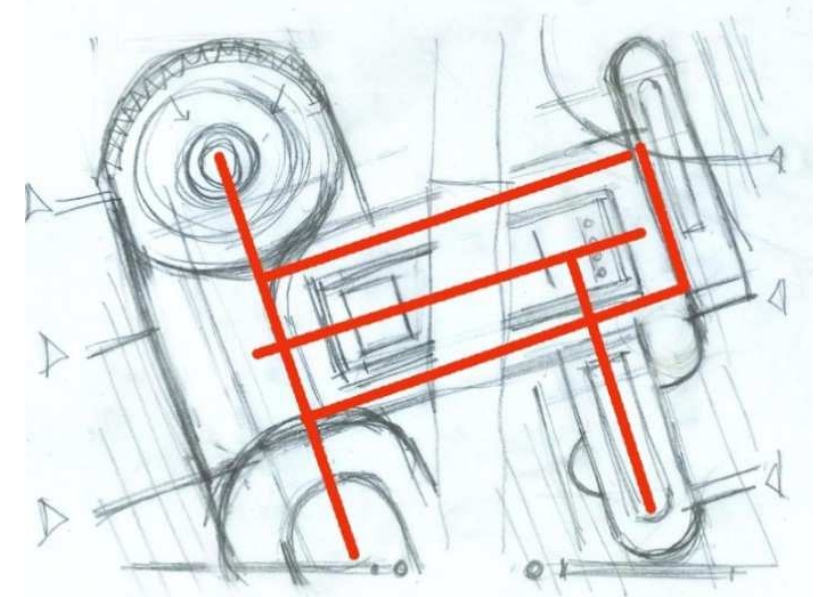

Figure 4. Fourth iteration of the design included a major reconstruction of the path systems, and a greater linking of the two blocks with cross-axial secondary regulating lines. These elements now form rectangular and orthogonal harmony.

The final design solution for the studio exercise is shown in Figure 5. At this phase, the student showed the inclusion of all of the design program elements including a performance stage (in the round), a paved space for large gatherings near the stage, an arbor shaded seating space at the edge of the large gathering space, restrooms, an entry feature with a rectangular fountain and pool, long linear paths for the set up and display of booths, secondary paths that link to the multi-modal elements such as the bus stop, an entry gate feature, vehicular parking and pedestrian cross walks.

Regarding the observation of regulating lines, the final stage of design editing produced the greatest improvement in strengthening harmony, unity and proportion. The harmony and unity was strengthened through the refinement of dominate and secondary regulating lines. The center of the park blocks also become a main feature of the park system that links the two blocks. The two blocks also become linked with pavement patterns that align to the street and provide contrast to the angled composition. The placement of the two long axis to each other in terms of proportion and within each block is much improved.

The system of regulating lines shown employs two nearly identical sized rectangles. These rectangles approach the golden rectangle in terms of their proportion (5:3). The Fibonacci numbering system [19] includes the sequence of 0 , $1,1,2,3,5,8,13$, etc. For the purpose of demonstrating the Fibonacci sequence, numbering was added to the regulating lines at the perimeter of the rectangle for comparison. Proportions used by the student approach these proportions but are not exact. Another round of editing could further refine the proportions of the program elements with the proportion of the golden section. The golden rectangle was not pointed out by the student, nor was the deliberate formation of the interaction between the two with a secondary rectilinear grid. It is interesting that the student intuitively resolved the two blocks each with resemblances of golden rectangles with the use of cross connecting regulating lines.

In the field of architecture, regulating lines on buildings are used not so much as axial alignments of dominant features located at the facade (entrances and windows), but more connectors across features such as windows in diagonal alignment with the height to width proportion of a building. In this student's design of the park, the boundary of the park will not change due to road and curb alignments. Thus, regulating lines could not be used to change the overall proportions of the park boundaries. Here, the regulating lines function to align program elements along axil lines. Invisible cross connecting axial lines between blocks in the park, reinforce the harmony between the two blocks. The midblock cross connecting regulating lines are directly aligned with pathways, but the secondary cross connecting lines of other features such as the performance stage (large block aligned with the shaded seating space in the small block) are subtle and not related to park features. However, it is the alignment of the secondary features that increases unity overall in the park. 


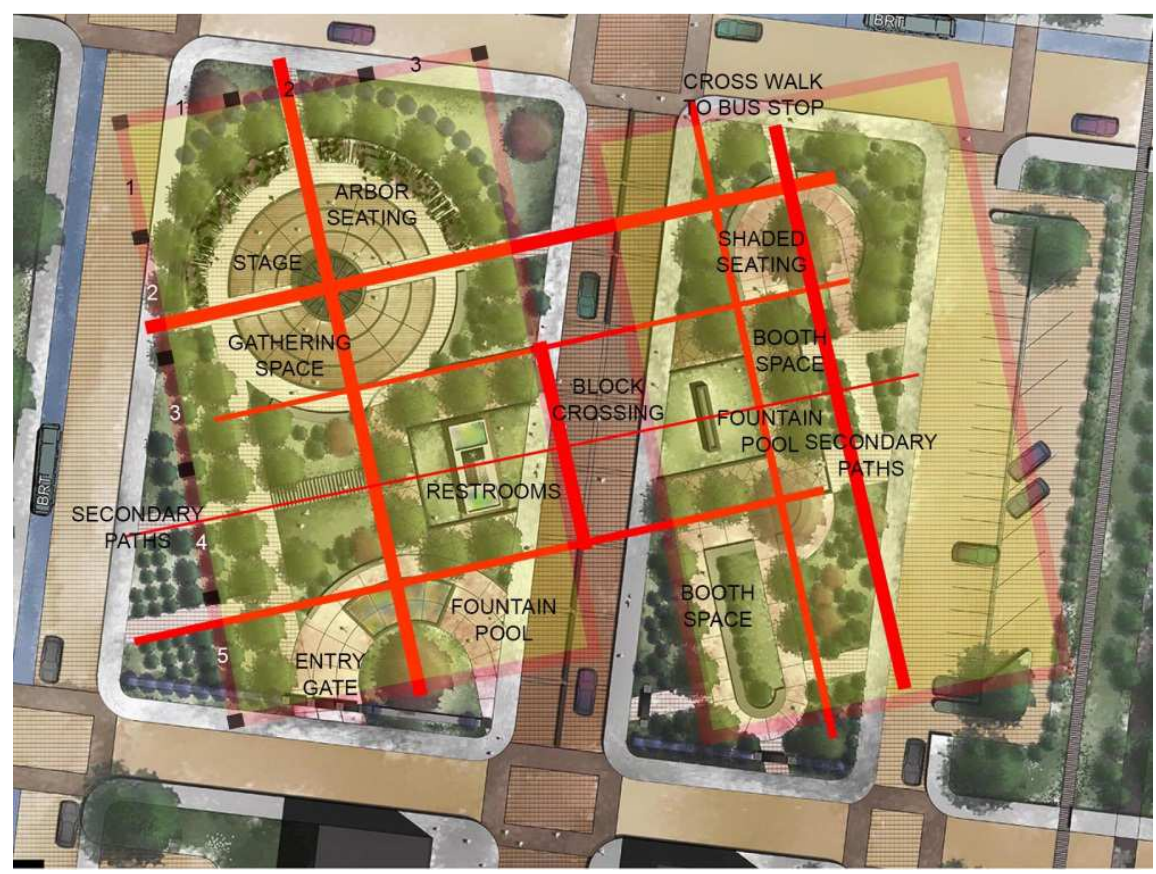

Figure 5. Final landscape design for the park. Regulating lines (shown in red) demonstrate that the student achieved greater unity and harmony in the final stage compared to stage 1. The golden rectangle can be seen as the proportions roughly follow the Fibonacci sequence and a 3:5 proportion and the cross alignment of blocks.

\section{Discussion and Conclusions}

In this case study, regulating lines were introduced as a concept to aid landscape architecture students in the design composition process prior to the beginning a landscape design project. During five iterations of the student's designs, the instructor discussed how awareness of regulating lines may improve design principles such as proportion, harmony and unity in their design. The student, at each phase of the design editing process, considered the alignment of regulating lines with the refinement of design elements and principles.

Near the beginning phase, the design principles and form compositions were weak in the case study example. Through a process of discussion, the instructor aided the student in the design process to align program elements, and to use regulating lines to align features within and between both blocks. The instructor did not directly dictate that the student implement regulating lines, but at times did draw lines on tracing paper overlays to suggest a potential revision direction. Through careful word selection during the design critiques, direction was given in simple dialog such as "increase unity between the two blocks" or "relate apparent regulating lines to common directional and compositional elements". The instructor did not design the project for the student. This temptation often leads to a fruitful design progress by the student, but little learning takes place. The use of regulating lines was explored here as a way to aid the student and the studio instructor during the critique process. This was done with the use of simple feedback to encourage the student to make those connections.

It appeared that the student in this example made good progress during most of the design iterations. At the fourth design iteration (Figure 4), the student made significant progress in terms of alignment of program features across the park blocks with an emphasis on program elements. This progression could have been from the student shifting the focus from the paths as a main feature of the park as regulating lines to the program elements as the dominant features. During the previous design iterations, the student used paths as dominant regulating lines, but the last design iteration phase the program elements became the dominant features with paths as secondary regulating elements. The student's preconceived ideas of a curving path as a main feature with an adjacent water channel were set aside. This change in focus better replicates effective use of regulating lines in buildings. Where regulating lines in buildings simply align vertical facade features such as windows or doors, there is not as much harmony overall as when cross diagonal arrangement of windows, doors, and facade outline determines overall composition and proportion [9]. With this landscape design study of the park, the student achieved a similar compositional effect by not focusing on the lines themselves but on the compositional effect of allowing aligned cross connections. It was this step that improved the proportion of the park features and unity. The proportion was improved as the student achieved two identical arrangements of park features aligned to form golden rectangles. With some additional editing, the design could be further refined to align features with the golden rectangle proportions.

During the studio, it was apparent that some students made use of regulating lines and learned how to design with them. The beginning designers were able to use regulating designs to help them; however, in discussions with them in the successive years, it was discovered that some students did not 
carry the concept to the next studio because it was one exercise and not considered as a method for any design problem.

In the practice of landscape architecture, regulating lines may be well-suited to projects with a simple site context and form. Diverse and complex settings however, may be difficult to resolve with emphasized regulating lines or grids. The design of some informal compositions may not be aided by regulating lines such as meandering designs or a site with excessive vertical change.

In this case study, the placement of design program features aligned according to design principles, allowed the student to achieve harmony, unity and repetition in the park composition. Since there were no control groups, it is difficult to determine to what degree the use of regulating lines had during the design process.

\section{Acknowledgements}

An earlier version of this paper was presented at the Council of Educators in Landscape Architecture (CELA) annual conference, May 26-29, 2017, Beijing, China. Revised and reviewed here, with permission from CELA.

\section{References}

[1] Hing, A., Understanding the Plan: A Studio Experience. Journal of Interior Design, 2006. 31(3): p. 10-20.

[2] Elam, K., Geometry of design: studies in proportion and composition. 2001: Princeton Architectural Press.

[3] Motloch, J. L., Introduction to landscape design. 2000: John Wiley \& Sons.

[4] Lauer, D. A. and S. Pentak, Design basics. 2011: Cengage Learning.

[5] Booth, N. K., Basic elements of landscape architectural design. 1989: Waveland press.
[6] Booth, N. K. and J. E. Hiss, Residential landscape architecture: design process for the private residence. 2011: Prentice Hall.

[7] Reid, G. W., From concept to form in landscape design. 1993.

[8] Ching, F. D., Architecture: Form, space, and order. 2014: John Wiley \& Sons.

[9] Hale, J., The old way of seeing. 1994: Houghton Mifflin Harcourt.

[10] Doczi, G., The power of limits: proportional harmonies in nature, art, and architecture. 1981.

[11] Kolarevic, B., Regulating lines and geometric relations as a framework for exploring shape, dimension and geometric organization in design, in CAAD futures 1997. 1997, Springer. p. $163-170$.

[12] Mallgrave, H. F. and C. Contandriopoulos, Architectural theory. 2 vols. Vol. 1 an Ontology from Vitruvius to 1870, Malden, MA. 2006, Blackwell Pub.

[13] Pregill, P. and N. Volkman, Landscapes in history: design and planning in the Eastern and Western traditions. 1999: John Wiley \& Sons.

[14] Van Tonder, G. J., M. J. Lyons, and Y. Ejima, Perception psychology: Visual structure of a Japanese Zen garden. Nature, 2002. 419(6905): p. 359-360.

[15] Hansen, A., From hand to land: tracing procedural artifacts in the built landscape. Scenario 01: Landscape Urbanism, 2011.

[16] Bell, S., Elements of visual design in the landscape. 2004: Taylor \& Francis.

[17] Dvorak, B., et al., Multimodal Transportation Systems and Transit Oriented Development: Concepts for Bryan-College Station, Texas, and Texas A\&M University. 2015, Publisher: Blurb.com: United States. p. 146.

[18] Dreiseitl, H. and D. Grau, New waterscapes: Planning, building and designing with water. 2009: Walter de Gruyter.

[19] Murphy, M., Landscape architecture theory. Waveland Pr Inc, 2005. 